\section{Cost-Effectiveness of Recombinant Human TNK Tissue-Type Plasminogen Activator (Rhtnk-Tpa) Versus Recombinant Tissue Plasminogen Activator (Rt-PA) in Treating ST- Elevation Myocardial Infarction (STEMI)}

\section{Abstract}

Objective: While the clinical effect of rhTNK-tPA in STEMI treatment has been established, the economic effect of adopting the new therapy (rh-TNK-tPA) is still unclear. The present study aimed to examine the cost-effectiveness of rhTNK-tPA compared with rt-PA in the Chinese setting.

Methods: A Markov model was constructed to conduct the cost-effectiveness analysis from a third-party payer perspective. Costs of $\mathrm{PCl}$, rehabilitation after discharge, CABG, myocardial ischemia recurrence, cardiac shock, reinfarction, and adverse events were considered. Clinical effectiveness data were obtained from the pivotal phase II clinical trial. Sensitivity analyses were conducted to examine the robustness of the base-case findings.

Results: The total cost of treatment for the 30 days after STEMI onset in the rhTNK-tPA and rt-PA arms were $¥ 30,846$ and $¥ 31,314$, respectively. The QALYs of rhTNK-tPA and rtPA arms were 0.0345 and 0.0343 respectively. RhTNK-tPA was dominant. The total cost of lifetime in the rhTNK-tPA and rt-PA arms were $¥ 134,519$ and $¥ 134,311$, respectively. The corresponding QALYs in the rhTNK-tPA and rt-PA arms were 6.397 and 6.356, respectively. The ICER of rhTNK-tPA vs. rt-PA treatment was $¥ 5,020 / Q A L Y$. The sensitivity analyses showed that rhTNK-tPA was dominant in most scenarios.

Conclusions: RhTNK-tPA therapy is cost-saving and more effective compared with rt-PA for STEMI treatment in the Chinese population.

Keywords: rhTNK-tPA; rt-PA; ST-elevation myocardial infarction; Cost-effectiveness analysis

Received: February 23, 2018; Accepted: March 23, 2018; Published: April 04, 2018

\section{Shuiqing $\mathrm{ZHU}^{1}$, Hongjun Yin', Dennis Xuan², Dunming Xiao', Yingrui $\mathrm{Xu}^{3}$, Qin Yang ${ }^{4}$ and Jianwei Xuan ${ }^{5 *}$ \\ 1 Shanghai Centennial Scientific Co. Ltd, Xuhui, Shanghai, China \\ 2 University of North Carolina at Chapel Hill, NC, USA \\ 3 Sun Yat-Sen University, Xingang, China \\ 4 Guangzhou Recomgen Biotech Co. Ltd, Luogang, China \\ 5 Sun Yat-Sen University Health Economic Research Institute, Haizhu, China}

\section{*Corresponding author: Shuiqing ZHU \\ झxuanjww3@mail.sysu.edu.cn}

Guangzhou, Shanghai Centennial Scientific Co. Ltd, China

Tel: 15201924528

Citation: ZHU S, Yin H, Xuan D, Xiao D, Xu Y, et al. (2018) Cost-Effectiveness of Recombinant Human TNK Tissue-Type Plasminogen Activator (Rhtnk-Tpa) Versus Recombinant Tissue Plasminogen Activator (Rt-PA) in Treating ST-Elevation Myocardial Infarction (STEMI). J Health Med Econ Vol.4 No.1:2

\section{Introduction and Background}

(STEMI is one of the two types of acute myocardial infarction $\mathrm{MI}$ ), defined by characteristic symptoms of $\mathrm{MI}$ in association with persistent electrocardiographic (ECG) ST-elevation and subsequent release of biomarkers of myocardial necrosis [1-3]. The incidence of AMI ranks fourth in all cardiovascular diseases (Cardiovascular disease report 2015 of China) [4]. According to a recent study by Chinese Centre for Disease Control and Prevention (CCDC), the incidence of AMI among Chinese adults was 0.44 [5] and $0.54 \%$ ofor urban Chinese adults [5]. The mortality of AMI has been increasing rapidly in China in recent years. In 2014, it was 55.32 per 100,000 residents in urban areas and 68.6 per 100,000 residents in rural areas [5]. The World Bank estimated that $\mathrm{Ml}$ and stroke would account for more than $50 \%$ of the chronic disease burden in the Chinese population between 2010 and 2030, which poses a huge threat to public health. The disease burden of AMI in China was 6.83 disability-adjusted life years (DALYs) per 1,000 persons, $75.26 \%$ of which was years of life lost (YLL)

There are three treatments available for STEMI including fibrinolytic therapy, percutaneous coronary intervention $(\mathrm{PCl})$, and coronary artery bypass graft (CABG) [6]. According to the ESC Guidelines for the Management of AMI in Patients Presenting with ST-Segment Elevation [7], fibrinolytic therapy is recommended for the following situations [8]: patients with symptoms of $<12$ $\mathrm{h}$ duration and persistent STEMI or (presumed) new left bundle branch block; patients with evidence of on-going ischemia even 
if symptoms may have started $>12 \mathrm{~h}$ beforehand or if pain and ECG changes have been stuttering; or reperfusion therapy with primary $\mathrm{PCl}$ for stable patients presenting $12-24 \mathrm{~h}$ after symptom onset. The benefit of fibrinolytic therapy in patients with STEMI is well established [9]. Fibrinolytic therapy is particularly important in those settings where primary $\mathrm{PCl}$ cannot be offered to STEMI patients within the recommended timelines [10].

TNK tissue-type plasminogen activator is a tissue plasminogen activator (tPA) produced by recombinant DNA technology using an established mammalian cell line (Chinese hamster ovary cells) [11]. It is a recombinant fibrin-specific plasminogen activator that is derived from native t-PA by modifications at three sites of the protein structure. It binds to the fibrin component of the thrombus (blood clot) and selectively converts thrombus-bound plasminogen to plasmin, which degrades the fibrin matrix of the thrombus. Recombinant human TNK tissue-type plasminogen activator (rhTNK-tPA) is a new type of TNK-tPA, which has higher fibrin specificity and greater resistance to inactivation by its endogenous inhibitor (PAI-1) compared to native t-PA. A latest study demonstrated that rhTNK-tPA $20 \mathrm{mg}$ is effective and safe for Chinese patients with acute myocardial infarction and there is a statistically significant superiority of rhTNK-tPA over rt-PA in terms of patency rate as determined by coronary angiography at $90 \min [12]$.

Although the clinical benefit of rhTNK-tPA has been established, the economic effect of adopting the new treatment into STEMI treatment is still unclear. The present study aimed to examine the cost-effectiveness of rhTNK-tPA compared with rt-PA in the Chinese setting.

\section{Methods}

\section{Overview}

A Markov model was constructed to conduct the costeffectiveness analysis comparing rhTNK-tPA with rt-PA from the perspective of a third-party payer. We conducted a thorough review on costs of $\mathrm{PCl}$, rehabilitation after discharge, CABG, myocardial ischemia recurrence, cardiac shock, reinfarction, and adverse events. Given the limited cost data available in literature, a survey given to key opinion leaders (KOLs) was carried out to estimate additional cost items. Clinical effectiveness data were obtained from the pivotal phase II clinical trial [12].

\section{The pivotal phase II trial}

A multi-centre, blinded, randomized, controlled trial was conducted to compare rhTNK-tPA and rt-PA. Detailed descriptions of the trial design, inclusion and exclusion criteria, baseline characteristics, and findings were previously published [12]. From July 2005 to May 2007, 251 patients were enrolled. The rhTNK-tPA was administered by an intravenous bolus of 20 mg over 5 10s. The rt-PA was administered by an intravenous bolus of $8 \mathrm{mg}$ followed by infusion of $42 \mathrm{mg}$ over 90 minutes primary endpoint was TIMI flow of the infarct-related artery (IRA) by coronary angiography at $90 \mathrm{~min}$ after initiation of treatment The secondary endpoints include 30-day mortality rate, 30-day reinfarction rate, myocardial ischemia recurrence, revascularization and related complications.

\section{Model structure}

Using Excel, a Markov model was developed to simulate the progression of STEMI (Figure 1). The model was used to estimate the direct costs associated with rhTNK-tPA and rt-PA treatments for STEMI and the cost-effectiveness. Health benefits were measured in quality-adjusted life years (QALYS). Incremental cost-effectiveness ratio (ICER) was calculated by dividing the cost difference by the difference in QALYs for time spans of 30 days, 1 year, 5 years and lifetime. One-way sensitivity and probabilistic sensitivity analyses were performed to test the robustness of the model.

\section{Clinical inputs}

Model input parameters were drawn from the pivotal phase II clinical trial and other published literature. The classification of TIMI after 30 days based on the pivotal trial are presented in Table 1 [13]. TIMI grade related mortality in 30 days, different TIMI grade under the age of 60, TIMI grade related mortality of different genders in 30 days, mortality among general population were from the literature and a meta-analysis (Table 2) [13-16].

The secondary efficacy endpoints including $\mathrm{PCl}$ in 90 minutes after admission (first 30 days), coronary artery bypass graft (CABG), myocardial ischemia recurrence, cardiac shock and reinfarction of rhTNK-tPA and rt-PA based on phase II pivotal trial [12] are presented in Table 3.

The adverse reactions reported in the pivotal phase II trial included intracranial haemorrhage and minor bleeding [12]. The incidence rate of intracranial haemorrhage was $0.81 \%$ and $0.79 \%$ for the rhTNK-tPA and rt-PA arms, respectively. The rate of minor bleeding was $16.94 \%$ and $17.32 \%$ for the rhTNK-tPA and rt-PA arms, respectively.

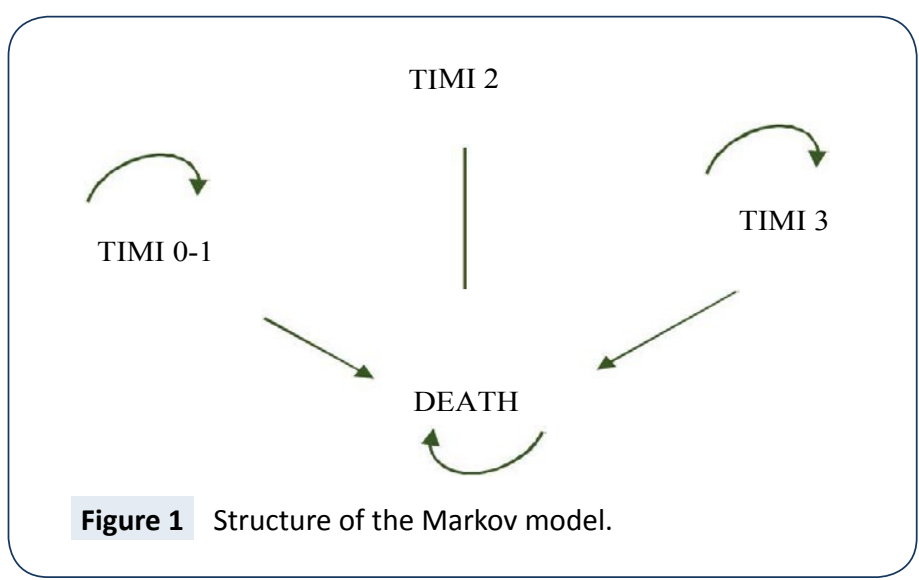

Table 1: The classification of TIMI within 30 days after AMI onset.

\begin{tabular}{|c|c|c|c|}
\hline TIMI classification & rhTNK-tPA (\%) & rt-PA (\%) & Distribution \\
\hline TIMI grade 0/1 & 17.2 & 32.58 & Beta \\
\hline TIMI grade 2 & 17.21 & 13.49 & Beta 1-Ptimi grade \\
\hline TIMI grade 3 & 65.59 & 53.93 & 0/1-pTIMI grade 2 \\
\hline
\end{tabular}


Table 2: Mortality risk among the patients and general population.

\begin{tabular}{|l|c|c|c|}
\hline Item & \multicolumn{2}{|c|}{ Defaults } & \multicolumn{2}{c|}{ Distribution } & Data sources \\
\hline TIMI grade related mortality in $\mathbf{3 0}$ days & (RR) & \\
\hline TIMI grade 0/1 & 1 & constant & {$[14]$} \\
\hline TIMI grade 2 & 0.77 & Beta & {$[14]$} \\
\hline TIMI grade 3 & 0.41 & Beta & {$[14]$} \\
\hline 30-days mortality in TIMI grade 0/1 by & & \\
\hline Male & 6.91 & Beta & {$[15]$} \\
\hline Female & 14.44 & Beta & {$[15]$} \\
\hline Mortality among & & & \\
\hline STEMI patients vs. & 3.7 & LogNorma & {$[16]$} \\
\hline general & & & \\
\hline people (RR) & & & \\
\hline Mortality rate among general population & (\%) & \\
\hline $50-54$ & 0.55 & Beta & {$[17]$} \\
\hline $55-59$ & 0.8 & Beta & {$[17]$} \\
\hline $60-64$ & 1.3 & Beta & {$[17]$} \\
\hline $65-69$ & 2.13 & Beta & {$[17]$} \\
\hline $70-74$ & 3.7 & Beta & {$[17]$} \\
\hline $75-79$ & 5.91 & Beta & {$[17]$} \\
\hline $80-84$ & 9.86 & Beta & {$[17]$} \\
\hline Females (by age group) & & & {$[17]$} \\
\hline $50-54$ & 0.28 & Beta & {$[17]$} \\
\hline $55-59$ & 0.43 & Beta & {$[17]$} \\
\hline $60-64$ & 0.75 & Beta & {$[17]$} \\
\hline $65-69$ & 1.31 & Beta & {$[17]$} \\
\hline $70-74$ & 2.44 & Beta & {$[17]$} \\
\hline $75-79$ & 4.09 & Beta & {$[17]$} \\
\hline $80-84$ & 7.4 & Beta & {$[17]$} \\
\hline
\end{tabular}

Table 3: Rate of secondary efficacy endpoints under rhTNK-tPA and rtPA (\%).

\begin{tabular}{|c|c|c|c|}
\hline Secondary Efficacy Endpoint & rhTNK-tPA & rt-PA & Distribution \\
\hline $\begin{array}{c}\text { PCl in 90 minutes after } \\
\text { admission (first 30 days) }\end{array}$ & 24.19 & 15.75 & Beta \\
\hline $\begin{array}{c}\text { CABG } \\
\text { Myocardial ischemia } \\
\text { recurrence }\end{array}$ & 0 & 0.79 & Beta \\
\hline CGS(cardiac shock) & 1.61 & 2.36 & Beta \\
\hline Reinfarction & 1.61 & 2.36 & Beta \\
\hline
\end{tabular}

Table 4: Healthcare costs for STEMI patients.

\begin{tabular}{|c|c|c|c|}
\hline Variable & Cost ( $¥)$ & Data resources & Distribution \\
\hline rhTNK-tPA (16 mg) & 7350 & $\begin{array}{c}\text { Guangzhou Recomgen } \\
\text { Biotech }\end{array}$ & Gamma \\
\hline rt-PA (50 mg) & 5540 & National biding price & Gamma \\
\hline $\mathrm{PCl}$ per patient & 35000 & KOLs & Gamma \\
\hline Recovery care per year & 10000 & KOLs & Gamma \\
\hline CABG & 100000 & KOLs & Gamma \\
\hline $\begin{array}{l}\text { Myocardial ischemia } \\
\text { Reccurence }\end{array}$ & 25000 & KOLs & Gamma \\
\hline Cardiac shock & 20000 & KOLs & Gamma \\
\hline Reinfarction & 50000 & KOLs & Gamma \\
\hline $\begin{array}{l}\text { Intracranial } \\
\text { hemorrhage }\end{array}$ & 20000 & KOLS & Gamma \\
\hline Minor bleeding & 10000 & KOLS & Gamma \\
\hline
\end{tabular}

\section{Resource use and costs}

The costs of drugs were provided by the manufacturer or based on national bidding price. The other costs used in the analysis were based on a survey to KOLs from cardiology and cardiac surgery departments of Class III Grade A hospitals in Beijing, Shanghai, Guangzhou, Foshan, Zhanjiang, Chengdu, and Xi'an.

\section{Quality of life adjustment}

To estimate QALYs, it was necessary to apply utility value to adjust the quality for the average Period of time of survival within the time span of the model, using an appropriate utility or Preference score. The utility of AMI onset (first 30 days) and longterm utility reduction due to AMI was from the literature $[17,18]$ (Tables $\mathbf{4}$ and $\mathbf{5}$ ). The utility of the general population of different gender and age groups were based on the values provided in a study by Dempster et al. (Table 5) [19].

\section{Analysis}

The base-case analyses were undertaken on a cohort at the age of 55 years and $85 \%$ males. A deterministic model was run on STEMI patients with the value inputs of all necessary parameters.

The total costs and QALYs in the rhTNK-tPA and rt-PA arms during the 30 days, 1 year, 5 years, and Lifetime of patients were calculated and compared, respectively. Considering that there is insufficient evidence to determine whether the secondary efficacy endpoints in the pivotal phase II trials are directly related

Table 5: Utilities of disease states and general population.

\begin{tabular}{|l|c|c|c|}
\hline Disease state or population & Utility & Distribution & Sources \\
\hline AMI onset (30 days) & 0.44 & Triangular & {$[18]$} \\
\hline $\begin{array}{l}\text { Death } \\
\text { Long term utility reduction due } \\
\text { to AMI }\end{array}$ & -0.127 & Triangular & {$[18]$} \\
\hline Male (by age group) & & & \\
\hline $50-54$ & 0.793 & Triangular & {$[20]$} \\
\hline $55-59$ & 0.774 & Triangular & {$[20]$} \\
\hline $60-64$ & 0.751 & Triangular & {$[20]$} \\
\hline $65-69$ & 0.725 & Triangular & {$[20]$} \\
\hline $70-74$ & 0.701 & Triangular & {$[20]$} \\
\hline $75-79$ & 0.684 & Triangular & {$[20]$} \\
\hline $80-84$ & 0.662 & Triangular & {$[20]$} \\
\hline $85+$ & 0.661 & Triangular & {$[20]$} \\
\hline Female (by age group) & & & \\
\hline $50-54$ & 0.772 & Triangular & {$[20]$} \\
\hline $55-59$ & 0.752 & Triangular & {$[20]$} \\
\hline $60-64$ & 0.728 & Triangular & {$[20]$} \\
\hline $65-69$ & 0.702 & Triangular & {$[20]$} \\
\hline $70-74$ & 0.685 & Triangular & {$[20]$} \\
\hline $75-79$ & 0.669 & Triangular & {$[20]$} \\
\hline $80-84$ & 0.655 & Triangular & {$[20]$} \\
\hline $85+$ & 0.643 & Triangular & {$[20]$} \\
\hline
\end{tabular}


to the tested drugs, two scenarios of analysis were conducted with or without the secondary efficacy endpoints considered. All costs and utilities were discounted by $3 \%$ per year.

Sensitivity analyses including one-way sensitivity and probabilistic sensitivity analysis (PSA) conducted to examine the impact of variation in 30-day mortality among TIMI grade $0 / 1$ male and female patients, percentage of $\mathrm{PCl}$ within 90-minute among TIMI grade 0-2 patients, utility of AMI (30 days), long-term utility reduction due to AMI, cost of rhTNK-tPA, cost of rt-PA, cost of $\mathrm{PCl}$, annual cost of long-term rehabilitation, difference in $\mathrm{PCl}$ within 90 minutes of admission in 30 days between rhTNK-tPA and rt-PA, and cost of CABG.

\section{Results}

\section{Base-case considering the secondary efficacy endpoints}

The total cost of treatment for the 30 days after STEMI onset in the rhTNK-tPA and rt-PA arms were

$¥ 30,846$ and $¥ 31,314$, respectively (Table 6). The QALYs of rhTNKtPA and rt-PA arms were 0.0345 and 0.0343 respectively. The ICER of rhTNK-tPA vs. rt-PA treatment was $-¥ 2,089,473 /$ QALY.

The total cost of lifetime in the rhTNK-tPA and rt-PA arms were $¥ 134,519$ and $¥ 134,311$, respectively (Table 6). The QALYs in the rhTNK-tPA and rt-PA arms were 6.397 and 6.356 respectively. The ICER of rhTNK-tPA vs. rt-PA treatment was $¥ 5,020 / Q A L Y$.

\section{Base-case without considering the secondary efficacy endpoints}

Without considering the secondary efficacy endpoints, the total cost of treatment for the 30 days after STEMI onset in the rhTNKtPA and rt-PA arms were $¥ 21,250$ and $¥ 23,555$, respectively (Table 7). The QALYs of rhTNK-tPA and rt-PA arms were 0.0345 and 0.0343 , respectively. The ICER of rhTNK-tPA vs. rt-PA treatment was $-¥ 10,280,120 /$ QALY.

Table 6: Total cost of treatment, QALY and ICER of rhTNK-tPA and rt-PA considering secondary efficacy endpoints.

\begin{tabular}{|c|c|c|}
\hline Item & rhTNK-tPA & rt-PA \\
\hline \multicolumn{3}{|l|}{30 days } \\
\hline Cost (¥) & 30846 & 31314 \\
\hline QALY & 0.0345 & 0.0343 \\
\hline ICER (¥/QALY) & $-2,089,473$ (rhTNK-tPA is dominant) & \\
\hline \multicolumn{3}{|l|}{1 year } \\
\hline Cost (¥) & 40385 & 40791 \\
\hline QALY & 5870.47 & 5832.47 \\
\hline ICER ( $¥ / Q A L Y)$ & $-104,996$ (rhTNK-tPA is dominant) & \\
\hline \multicolumn{3}{|l|}{5 years } \\
\hline Cost (¥) & 73107 & 73303 \\
\hline QALY & 2.6512 & 2.6345 \\
\hline ICER ( $¥ / Q A L Y)$ & $-11,285$ (rhTNK-tPA is dominant) & \\
\hline \multicolumn{3}{|l|}{ Lifetime } \\
\hline Cost (¥) & 134519 & 134311 \\
\hline QALY & 6.267 & 6.226 \\
\hline ICER (¥/QALY) & 5,020 (rhTNK-tPA is dominant) & \\
\hline
\end{tabular}

Table 7: Total cost of treatment, QALY and ICER of rhTNK-tPA and rt-PA without considering secondary efficacy endpoints.

\begin{tabular}{|c|c|c|}
\hline Item & rhTNK-tPA & rt-PA \\
\hline \multicolumn{3}{|c|}{30 days } \\
\hline Cost $(¥)$ & 21250 & 23555 \\
\hline QALY & 0.0345 & 0.0343 \\
\hline ICER (¥/QALY) & \multicolumn{2}{|c|}{$-10,280,120$ (rhTNK-tPA is dominant) } \\
\hline \multicolumn{3}{|c|}{1 year } \\
\hline Cost (¥) & 30789 & 33032 \\
\hline QALY & 0.587 & 0.583 \\
\hline ICER (¥/QALY) & \multicolumn{2}{|c|}{$-579,349$ (rhTNK-tPA is dominant) } \\
\hline \multicolumn{3}{|c|}{5 years } \\
\hline Cost (¥) & 63511 & 65543 \\
\hline QALY & 26519.39 & 26349.16 \\
\hline ICER (¥/QALY) & \multicolumn{2}{|c|}{$-117,057$ (rhTNK-tPA is dominant) } \\
\hline \multicolumn{3}{|c|}{ Lifetime } \\
\hline Cost $(¥)$ & 1249231429 & 1265511599 \\
\hline QALY & 6.397 & 6.356 \\
\hline ICER ( $¥ / Q A L Y)$ & \multicolumn{2}{|c|}{$-¥ 39,204$ (rhTNK-tPA is dominant) } \\
\hline
\end{tabular}

The total cost of lifetime in the rhTNK-tPA and rt-PA arms were $¥ 124,923$ and $¥ 126,551$, respectively (Table 7). The QALYs in the rhTNK-tPA and rt-PA arms were 6.397 and 6.356, respectively. The ICER of rhTNK-tPA vs. rt-PA treatment was $-¥ 39,204 /$ QALY.

\section{Sensitivity analyses}

Sensitivity analyses were performed to examine the robustness of the base-case results incorporating the secondary efficacy endpoints (the conservative scenario). The ranges of the values of parameters examined in the sensitivity analyses are presented in Table 8. Given that the results of sensitivity analyses were similar between the different time horizons, only those of 30 days, 5 years and lifetime are presented (Figures 2-4). The model was most sensitive to change in values of the following parameters: difference in $\mathrm{PCl}$ within 90 minutes of admission in 30 days between rhTNK-tPA and rt-PA, the proportion of patients in TIMI 0-2 grade treated with $\mathrm{PCl}$ in 90 minutes, the cost of rhTNKtPA and the cost rt-PA. Probabilistic sensitivity analyses (PSA) were used to evaluate the impact of uncertainty across all the parameters simultaneously. The values of the input parameters were sampled from Gamma distributions for costs and from Beta distributions for utility values (except for long-term utility reduction due to $\mathrm{AMI}$ ). And probabilities or proportions were mainly subjected to Beta distributions.

The cost-effectiveness acceptability curves (CEACs) showed the preference of rt-PA and rhTNK-tPA when accounting for a range of cost-per-QALY thresholds. The CEAC plot (Figure 5) shows that when the threshold is larger than $¥ 5,050$, rhTNK-tPA has the higher probability to be cost-effective than rt-PA. And at the threshold of 3 times of GDP per capita of China $(¥ 53,980 * 3)$, rhTNK-tPA has the probability of $84.3 \%$ to be cost-effective against with rt-PA (15.7\%).

\section{Discussion}

RhTNK-tPA is a new thrombolytic treatment, which was shown to have better efficacy than rt-PA in a recent phase II trial (15). 
Table 8: Ranges of Parameters Used in the Sensitivity Analyses.

\begin{tabular}{|c|c|c|}
\hline Parameters & Base case & \\
\hline & Lower limit & Upper limit \\
\hline 30-day mortality among TIMI grade $0 / 1$ males (<60 yrs) (\%) & 6.91 & $(6.219-7.601)$ \\
\hline 30-day mortality among TIMI grade $0 / 1$ females (<60 yrs) (\%) & 14.44 & $(12.996-15.884)$ \\
\hline Patients in TIMI 0-2 grade treated with $\mathrm{PCl}$ in 90 minutes (\%) & 100 & $(70-100)$ \\
\hline Utility (30 days from AMI onset) & 0.44 & $(0.396-0.484)$ \\
\hline Long-term utility reduction due to $\mathrm{AMI}$ & -0.127 & $(-0.1143,-0.1397)$ \\
\hline Cost of rhTNK-tPA (¥) & 7350 & $(6,615-8,085)$ \\
\hline cost of rt-PA (¥) & 5540 & $(4,986-6,140)$ \\
\hline Cost of $\mathrm{PCl}(¥)$ & 35000 & $(30,555-48,761)$ \\
\hline Annual cost of long-term rehabilitation ( $¥)$ & 10000 & $(8,799-20,266)$ \\
\hline RhTNK-tPA vs rt-PA: difference in chance of $\mathrm{PCl}$ in $90 \mathrm{~min}$ to & 8.44 & $(0-10.00)$ \\
\hline Cost of CABG $(¥)$ & 100,000 & $(9,000-110.0000)$ \\
\hline
\end{tabular}

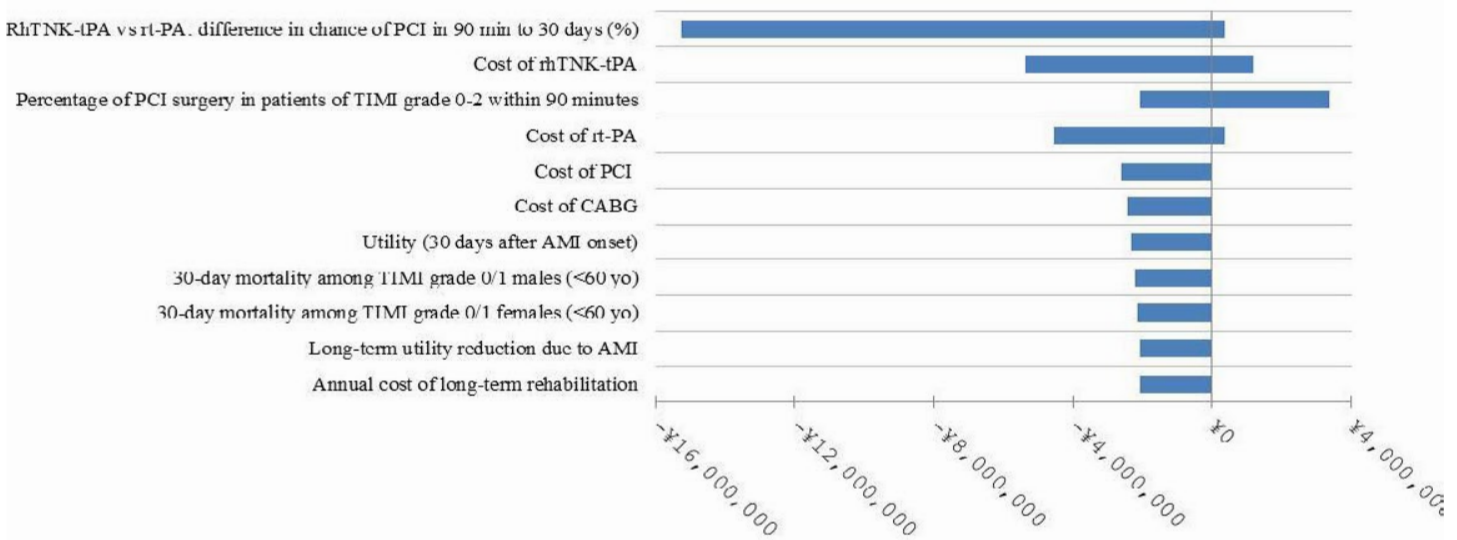

Figure 2 ICER changes as a result of change in input parameters (30 days).

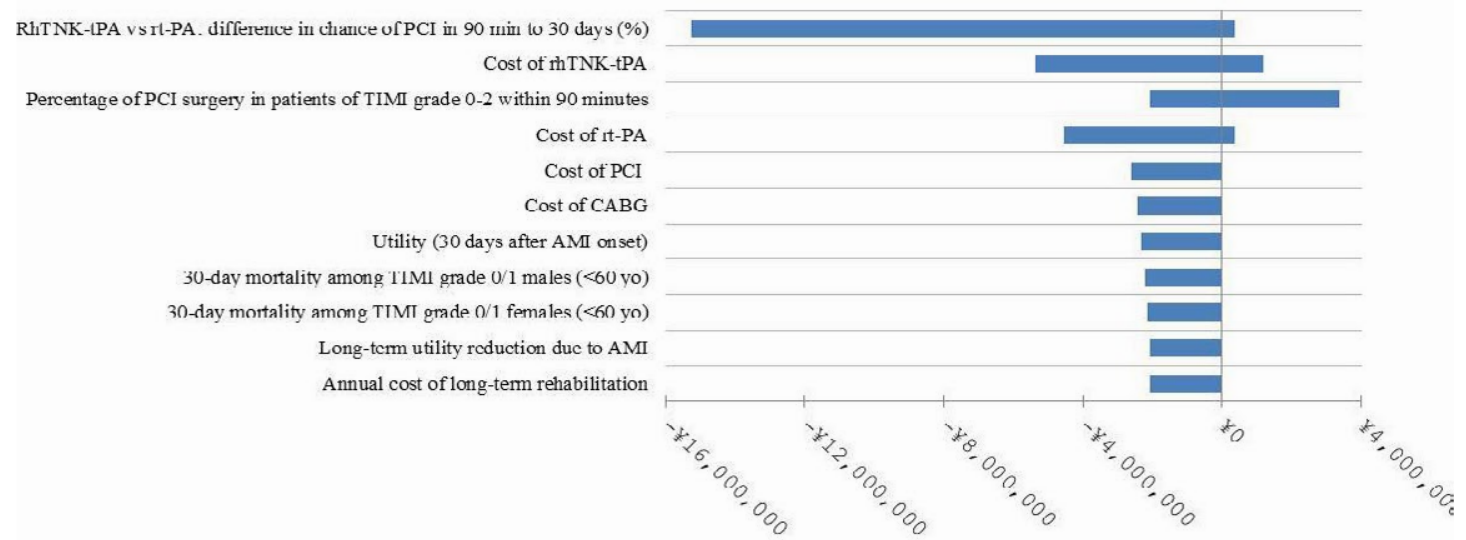

Figure 3 ICER changes as a result of change in input parameters (5 years).

A significantly greater coronary artery reperfusion in TIMI grade 2-3 patients and a higher rate of TIMI grade 3 of patients receiving rhTNK-tPA compared with those receiving rt-PA were demonstrated. According to a report in 2012 [20], rt-PA had been the only human tissue plasminogen activator available in China. With the introduction of RhTNK-tPA, practitioners have a more effective option than rt-PA. However, with limited healthcare resources especially in countries like China, economic evidence has become essential for the Ministry of Human Resources and Social Security and related authorities in China in decision making with regards to coverage of new healthcare technologies [21].

The present economic evaluation has shown that the rhTNKtPA arm was cost-effective compared with the rt-PA arm in the 


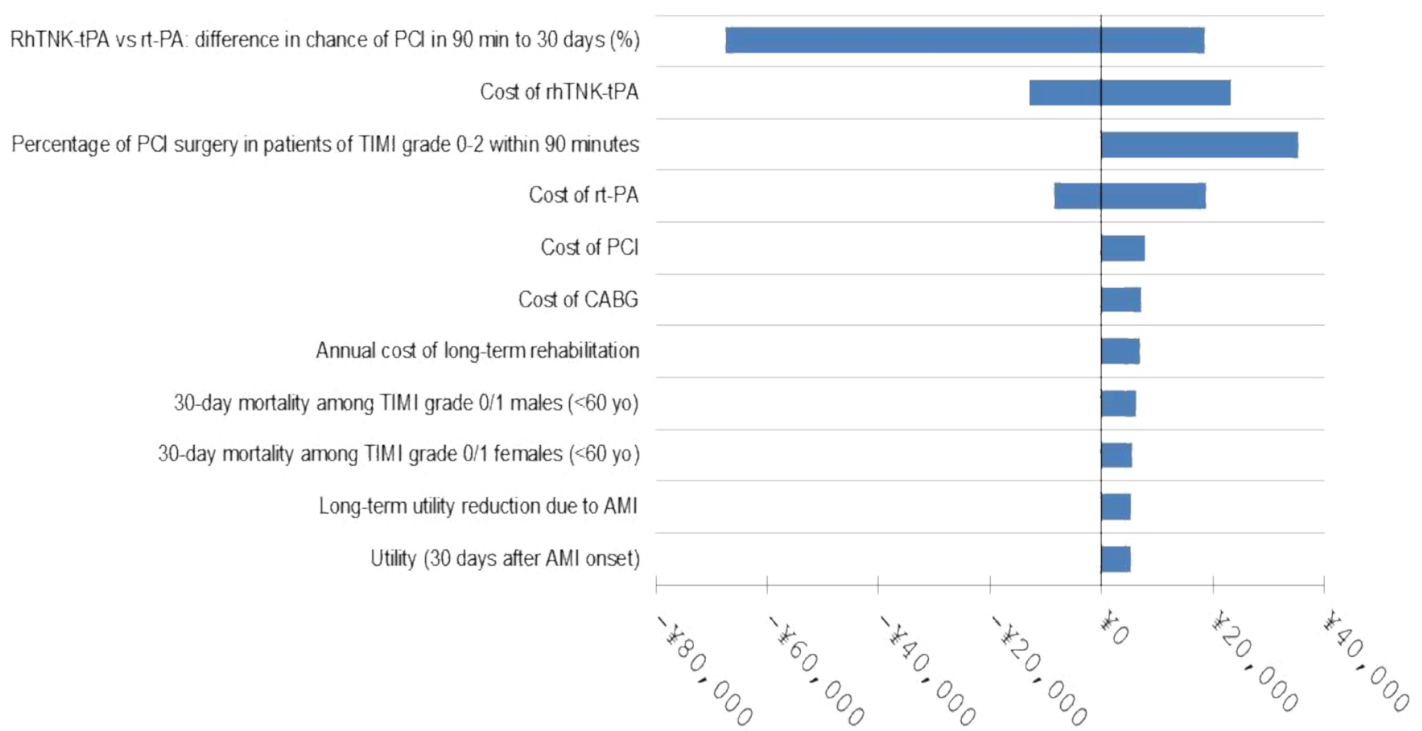

Figure 4 ICER changes as a result of change in input parameters (life-time) Cost-effectiveness acceptability curve.

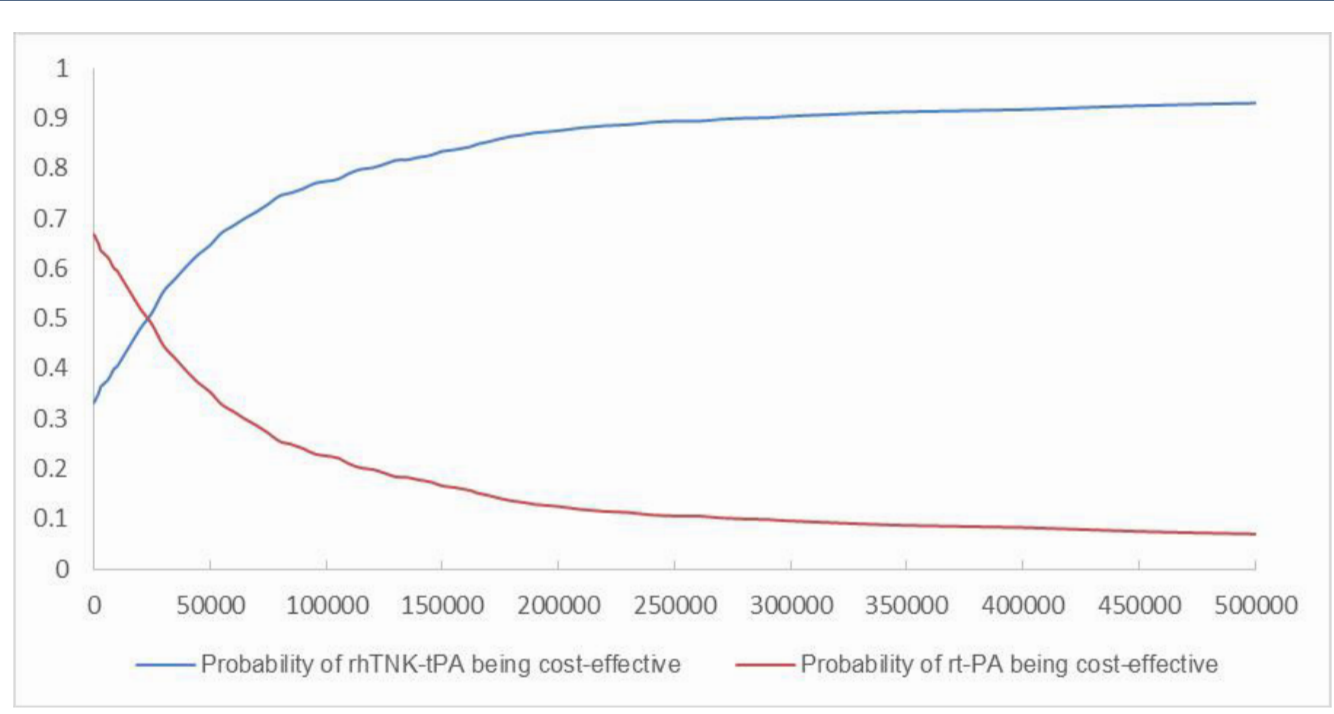

Figure 5 Cost-effectiveness Acceptability Curve.

different time horizons considered. The major drivers that rhTNKtPA arm was cost-effective lying on the significantly higher rate of TIMI grade 3, which resulted in much less need of $\mathrm{PCI}$ procedures, and lower rate of minor bleeding events. It is unknown whether the differences in myocardial ischemia recurrence, cardiac shock, reinfarction and needs of CABG were associated with the drugs. In 30-day time horizon, the effect of rhTNK-tPA arm and rt-PA arm were almost the same, so we conduct a cost-minimization analysis of course, the result is consistent with the costeffectiveness analysis.

The sensitivity analyses found that alternative assumptions generally showed lower costs and greater QALYs gained in the rhTNK-tPA arm for the 30-day time horizon except for the changes in the price of rhTNK-tPA or percentage of patients in TIMI 0-2 grade treated with $\mathrm{PCl}$ in 90 minutes. If the price of rhTNK-tPA becomes extremely high or percentage of patients in TIMI 0-2 grade treated with $\mathrm{PCl}$ in 90 minutes becomes extremely low, rhTNK-tPA may not be cost saving and the ICER for the 30 day time horizon may be above the WHO threshold ( 3 times of GDP per capita, $¥ 53,980 * 3$ in China in 2016) [22]. For the longer time horizons of 5 years or lifetime, the sensitivity analyses found that alternative assumptions showed that rhTNK-tPA is either dominant or with ICERs under WHO threshold in all scenarios [23]. The major driving factor for the lower ICER for the longer time horizons than 30 days is the significantly greater QALYs gained with rhTNK-tPA vs. rt-PA. 


\section{Limitations}

There are certain limitations to the present economic analysis. The extrapolation of survival in 5 years and lifetime assumes that the life expectancy is similar between patients receiving rhTNKtPA and those receiving rt-PA. A long-term follow-up study is needed to confirm this assumption.

Second, it was unknown whether the differences in secondary efficacy endpoints were due to the treatments compared. Such information would provide a more comprehensive understanding of the driving factors of costs saved by rhTNK-tPA vs. rt-PA. Third, part of the clinical data used to evaluate the cost-effectiveness of rhTNK-tPA was based on the safety and effective data in the phase II clinical trial. Therefore, the scientificity and rationality of the economic evaluation results are closely related to the preciseness, scientificity and rationality of the data based on the clinical trial. It is a rigorously designed and conducted head to head clinical trial with high quality. Therefore, the economic evaluation conclusion based on the study still has a high reference value, further studies with on-going phase III clinical trial's effectiveness and safety data also needed.

\section{Conclusion}

The present study demonstrated that rhTNK-tPA therapy is costsaving and more effective compared with rt-PA for the Chinese population. Our analysis can inform the decision about whether this should become the standard of care in China and the society itself must make the choice.

\section{References}

1 White HD, Thygesen K, Alpert JS, Jaffe AS (2014) Republished: Clinical implications of the Third Universal Definition of Myocardial Infarction. Heart 100: 424-432.

2 Physicians ACOE (2013) ACCF/AHA guideline for the management of ST-elevation myocardial infarction: a report of the American College of Cardiology Foundation/American Heart Association Task Force on Practice Guidelines. J Am Coll Cardiol 61: 78-140.

3 Thygesen K (2012) Third universal definition of myocardial infarction. Eur Heart J 33: 2506-2507.

4 Weiwei Chen (2015) China Cardiovascular Diseases. Chinese Medical Information Herald 2016: 1-10.

5 Puska P (2002) Nutrition and global prevention on non-communicable diseases. Asia Pac J Clin Nutr 11: 5755-5758.

6 Liu XT (2013) Disease burden of acute myocardial infarction of China in 2010. Chinese Journal of Prevention \& Control of Chronic Diseases.

7 Knuuti JM, Kolh P, Lancellotti P (2012) ESC Guidelines for the management of acute myocardial infarction in patients presenting with ST-segment elevation: the Task Force on the management of ST-segment elevation acute Myocardial infarction of the European Society of Cardiology (ESC). Eur Heart J 33:2569-2619.

8 Bonnefoy E (2009) Comparison of primary angioplasty and prehospital fibrinolysis in acute myocardial infarction (CAPTIM) trial: a 5-year follow-up. Eur Heart J 30: 1598-1606.

9 Bonnefoy E (2003) Primary angioplasty versus prehospital fibrinolysis in acute myocardial infarction: a randomised study. Lancet 360: 825829.

10 Pinto DS (2011) Benefit of transferring ST-segment-elevation myocardial infarction patients for percutaneous coronary intervention compared with administration of onsite fibrinolytic declines as delays increase. Circulation 124: 2512-2521.

11 Boersma E (1996) early thrombolytic treatment in acute myocardial infarction: reappraisal of the golden hour. Lancet 348: 771-775.
12 Mei Z (2016) Efficacy and safety of recombinant human TNK tissuetype plasminogen activator in patients with acute myocardial infarction. Chinese Journal of New Drugs.

13 Anderson JL, Karagounis LA, Califf RM (1996) Meta-analysis of five reported studies on the relation of early coronary patency grades with mortality and outcomes after acute myocardial infarction. Am J Cardiol 78: 1-8.

14 Zheng X, Dreyer RP, Hu S, Spatz ES, Masoudi FA, et al. (2015) Agespecific gender differences in early mortality following ST-segment elevation myocardial infarction in China. China PEACE Collaborative Group. Heart 101: 349-355.

15 Wagner M1, Goetghebeur M, Merikle E, Pandya A, Chu P (2009) Cost-effectiveness of intensive lipid lowering therapy with $80 \mathrm{mg}$ of atorvastatin, versus $10 \mathrm{mg}$ of atorvastatin, for secondary prevention of cardiovascular disease in Canada. Can J Clin Pharmacol 16: 331-345.

16 Wang M, Moran AE, Liu J, Coxson PG, Heidenreich PA (2014) Cost-effectiveness of optimal use of acute myocardial infarction treatments and impact on coronary heart disease mortality in China[J]. Circ Cardiovasc Qual Outcomes 7: 78-85.

17 The National Bureau of Statistics of the People's Republic of China. The sixth census data.

18 http://www.stats.gov.cn/tjsj/pcsj/rkpc/6rp/html/A0604a.htm

19 Dempster M, Donnelly M (2000) Measuring the health related quality of life of people with ischaemic heart disease. Heart 83: 641-644.

20 Shen LH (2012) Pharmacoinvasive therapy for ST elevation myocardial infarction in China: a pilot study. J Thromb Thrombolysis.

21 Growing Application of Pharmacoeconomics and Outcomes Research in Health-Care Decision-Making in the Asia-Pacific Region VIH.

22 World Health Organisation. Cost effectiveness and strategic planning (WHO-CHOICE).

23 Nijjar AP (2010) Ethnic and sex differences in the incidence of hospitalized acute myocardial infarction: British Columbia, Canada 1995-2002. BMC Cardiovasc Disord 10: 1-7. 